monográfico: Trasplante Renal. Experiencia del Hospital Clínico de Barcelona

Arch. Esp. Urol., 58, $6(497-501), 2005$

\title{
EVOLUCIÓN DEL TRASPLANTE RENAL DE DONANTE VIVO: DATOS HISTÓRICOS, ESTADÍSTICOS, NACIONALES Y PROPIOS.
}

\author{
M aría Pilar Altes Ineva, Pastor Alonso Paz, Harry Abadia, La ura Izquierdo Reyes, Federico \\ O ppenheimer y Ricardo Álvarez-Vijande.
}

Servicio de Urología y Transplante renal. ICN U. Hospital Clínico de Barcelona. Barcelona. España.

\begin{abstract}
Resumen.- El trasplante renal de donante vivo, a pesar de representar una minoría de la actividad trasplantadora total en nuestro país, es una buena alternativa de futuro, dado que la necesidad supera a la oferta de órganos de cadáver. Presentamos la evolución del trasplante renal de donante vivo en España, desde su inicio, basándonos en los datos de la O rganización $N$ acional de Trasplante, y nuestra situación actual respecto a otros países trasplantadores, así como los datos obtenidos de la experiencia en nuestro hospital, que se remonta al año 1965.
\end{abstract}

Palabras clave: Trasplante renal. Donante vivo.

\begin{abstract}
Summary.- Despite representing a small percentage of the transplant activity in our country, living donor kidney transplantation is a good alternative for the future because the needs exceed the offer of cadaver donor organs. W e present the evolution of living donor kidney transplantation in Spain from the beginning in accordance to the ONT (O rganización N acional de trasplantes), and our current situation in comparison with other countries, as well as data obtained from the experience in our hospital which began in 1965.
\end{abstract}

Keywords: Renal transplantation. Living donor.

\section{INTRODUCCIÓN}

Hace ahora 50 años, en la $\mathrm{N}$ avidad de 1954, se realizó el que puede ser primer trasplante renal de donante vivo con éxito. Fue en el Peter Bent Brigham Hospital de Boston, donde el equipo de Murray, Merryl y Harrison realizó un trasplante entre una pare-

Ricardo Álvarez Vijande

Servicio de Urología ja de gemelos univitelinos de 23 años.

Sin embargo en 1952, en el Hospital N ecker Hospital C línico Barcelona

C/ Villarroel, 170

08036 Barcelona. (España)

(París), se había realizado el primer trasplante de donante vivo. Un joven de 16 años fue trasplantado 
con un riñón de su madre. Inicialmente, la técnica resultó exitosa, pero a los 21 días un rechazo fulminante hizo fracasar esta primera experiencia.

Previamente, los primeros intentos de trasplante renal en humanos, principalmente realizados en Francia y Estados Unidos, con riñones de cadáver ó de recién nacidos anencéfalos, tuvieron escaso éxito.

De todo ello se intuyó la importancia de la histocompatibilidad entre donante y receptor, en el éxito del primer trasplante de donante vivo. Además el desarrollo de la diálisis como terapia sustitutiva renal, hizo que el diagnóstico de insuficiencia renal terminal dejase de ser sinónimo de mortalidad a corto plazo.

Posteriormente, gracias al estudio del sistema HLA y el inicio de la terapia inmunosupresora, se amplió la posibilidad de donación de vivo a familiares de menor grado y a donantes seleccionados.

Tras el desarrollo de los equipos de coordinación de trasplante y el inicio del empleo de la ciclosporina A como inmunosupresor de base en los años $80-90$, tomaron relevancia los programas de donante cadáver.

En el momento actual y en nuestro país, con la mayor eficacia de los inmunosupresores, la mayoría de injertos se obtienen de cadáver, siendo pequeña la proporción de trasplante renal de donante vivo (5), a pesar de las supervivencias alta mente satisfactorias de los injertos renales de cadáver, analizando períodos de similares pautas de tratamiento, el trasplante renal de vivo concede mejores resultados.

La contribución del trasplante renal de vivo al global de la actividad de trasplante renal es muy

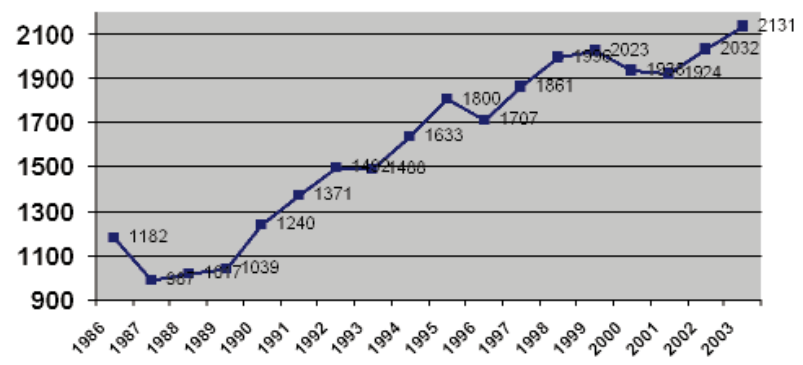

FIG URA 1. Trasplante renal. A ctividad en España. variable de unos países a otros, siendo las causas que motivan este hecho, diversas. Contribuyen de forma importante el grado de desarrollo económico, social y sanitario así como los motivos religiosos o culturales. A lgunos países que no aceptan los criterios de muerte cerebral, establecen sus programas de trasplante renal exclusivamente a través de donantes vivos, como son Japón e Irán.

\section{EVOLUCIÓN NACIONAL DEL TRASPLANTE RENAL DE VIVO}

La actividad de trasplante renal realizada en España ha sido prioritariamente de donante cadáver, a umentando de forma progresiva a lo largo de los últimos años, hasta duplicarse respecto a la actividad de hace 18 años. (Figura 1).

Por otra parte, el trasplante renal de donante vivo ha tenido un escaso desarrollo en nuestro país. Esta actividad, hasta el año 2000, había representa do siempre menos del $1 \%$ de la actividad total del trasplante.

En los últimos tres años, la proporción de trasplante de vivo respecto al total se ha incrementado de forma discreta. A sí pues, durante el año 2003 se han realizado en nuestro país 2131 trasplantes renales, de los que 60 eran de donante vivo, suponiendo estos el $2.81 \%$ del total. (Figura 2) Hay que destacar que el número de trasplantes de donante vivo se ha triplicado respecto a los que se hacían hace 3 años. (Figura 3.)

Estos hechos contrastan de forma llamativa con lo que sucede en otros países (Como son EEUU,

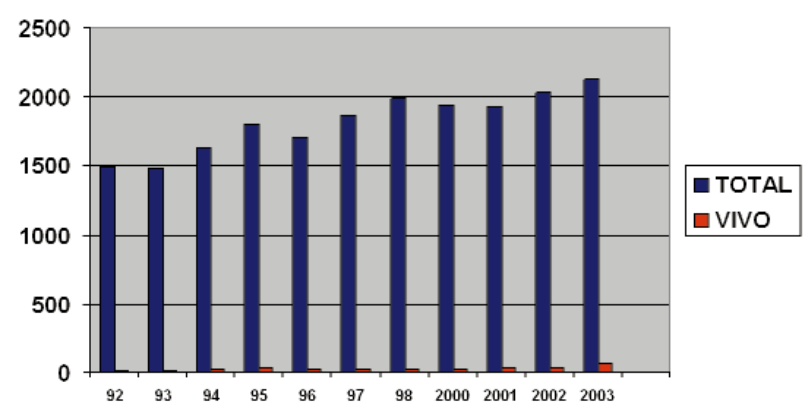

FIG URA 2. Trasplante renal total y de donante vivo. Actividad en España. 


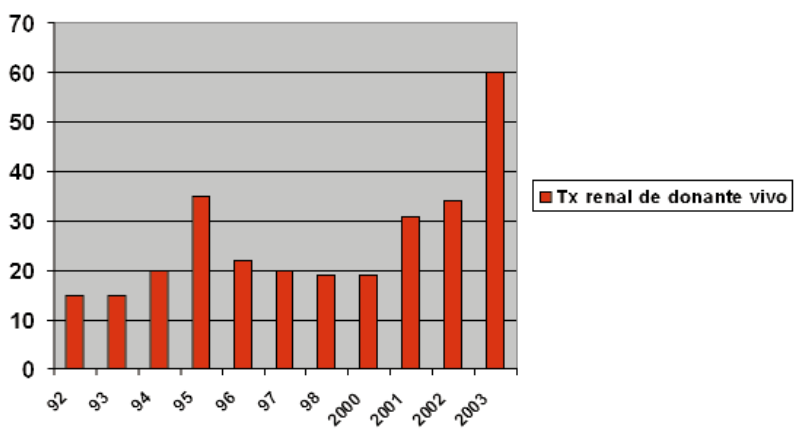

FIG URA 3. Trasplante renal de donante vivo. Actividad en España

Suecia, N oruega y Suiza) con una situación sanitaria similar cuando no superior a la nuestra, y al igual que nosotros sin limitaciones para acceder a otras formas de tratamiento sustitutivo (diálisis y Tx de cadáver), realizan un número superior de trasplante de vivo. (7) (Figura 4b)

A sí pues, durante el año 2003, en países vecinos como Francia y Portugal, la acividad de trasplante de donante vivo supuso respectivamente el $6.6 \%$ (2.3 pmp) y el $12.1 \%$ (4.2 pmp), del total de la actividad de trasplante renal. (Figura 4a)

En Italia esta actividad fue nula durante el mismo período. Destacan los países escandinavos, que

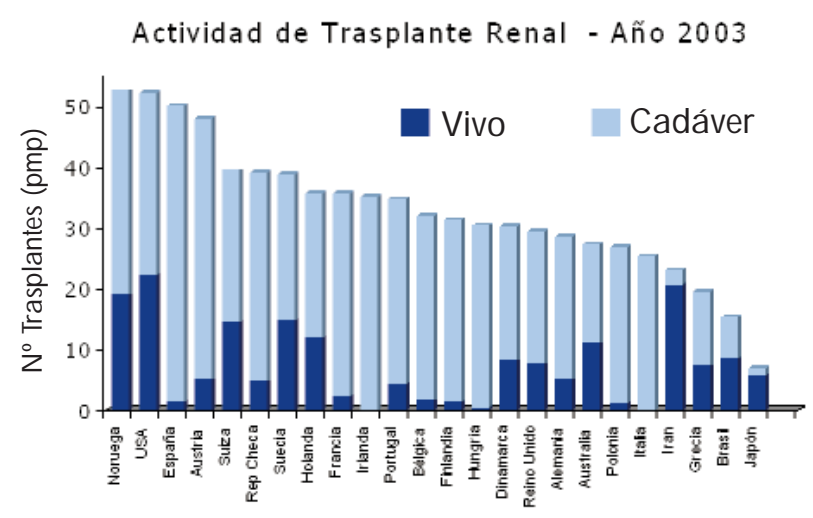

FIG URA 4a. Actividad en diferentes países trasplantadores. $N \cong$ de trasplantes renales PM P. Datos de la 0 rganización $N$ acional de Trasplantes. G ráfico publicado en http. www / ONT. Es. junto con Suiza, desde hace años presentan una tendencia creciente de la actividad de trasplante renal de vivo, quedando a la cabeza de Europa (5). El 37.6\% (14.6 pmp) del total de trasplante renal en Suecia fué de donante vivo, así como el 35.8 (18,9 pmp) en N oruega.

Irán y Japon, a pesar de tener una actividad trasplantadora total menor que España, (23 pmp y 12.5 pmp respectivamente), van a la cabeza en tanto por ciento de trasplante de donante vivo, con el 89.5 $\%$ y el $83.8 \%$. (Figuras $4 a$ y $4 b$ )

A pesar del descenso en el número de pacientes en lista de espera para trasplante renal en nuestro país, y el incremento paulatino en el número de trasplantes, todavía son muchos los pacientes en lista de espera, por lo que deben potenciarse todas las vías de obtención de órganos, como son el donante vivo y donantes a corazón parado. (Figura 5).

Desde que se han puesto en marcha los programas de donante vivo mediante laparoscopia (G ill 1994, Ratner 1995, Ratner 2001) se ha incrementado el número de trasplantes con órganos procedentes de personas allegadas al paciente. Al ser menor la agresión quirúrgica y más pronta la recuperación postoperatoria, muchos posibles candidatos a donación de riñón ven facilitada la decisión de ser donante.

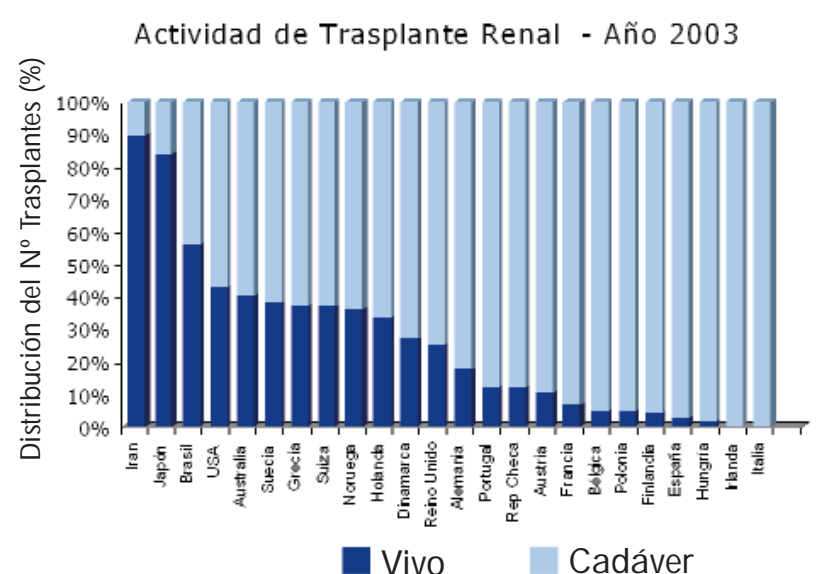

FIG URA 4b. Distribución de trasplantes de donante vivo en diferentes países trasplantadores. Datos de la O rganización $\mathrm{N}$ acional de Trasplantes 


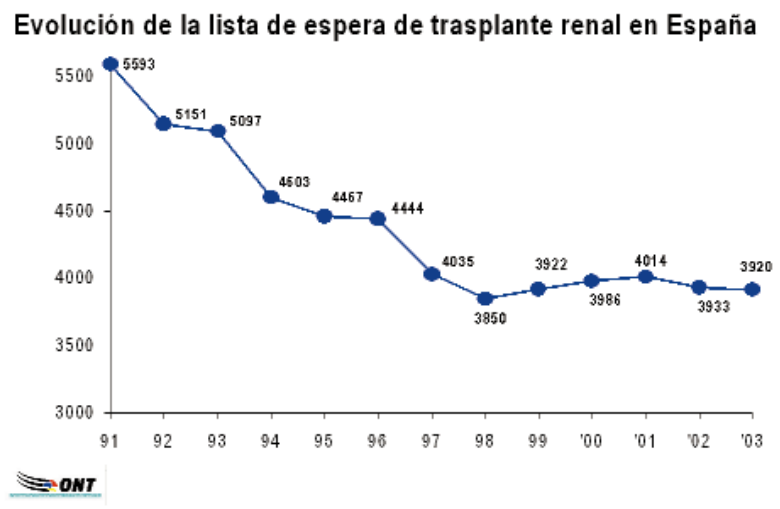

FIG URA 5.

\section{Hospital Clínico Barcelona Actividad de Trasplante Renal}

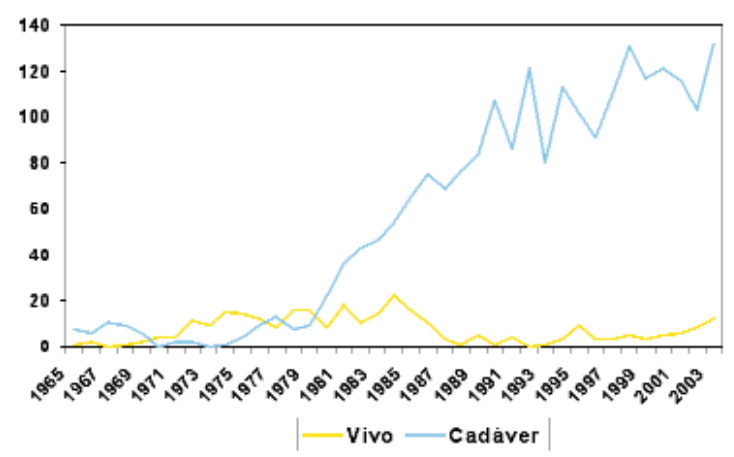

FIG URA 6.

\section{Casuística y resultados (1965-0 ctubre 2004)}

La actividad realizada en este centro se refiere a 285 trasplantes de vivo y representa el $11 \%$ del total de la actividad de trasplante renal del centro, con 2538 trasplantes renales realizados desde 1965 hasta el momento actual.

\section{Relación donante - receptor}

Del total de trasplantes se analizan 235 casos de los que obtenemos los siguientes datos: trasplante de hermano HLA idéntico con 54 trasplantes, HLA haploidénticos (padres y hermanos no idénticos) con 171 trasplantes, cónyuges con 6 trasplantes, y no relacionados con 1 trasplante; gemelos univitelinos con 3 trasplantes.

\section{Edad y sexo de donantes y receptores}

La edad media del donante vivo es de 49.74 años (rango 18-79), el $34.7 \%$ fueron mujeres, y el $65.2 \%$ hombres. En el caso de los receptores la edad media es de 28.9 años (rango 8.8-64 años), siendo hombres el $64.19 \%$ y mujeres el $35.8 \%$.

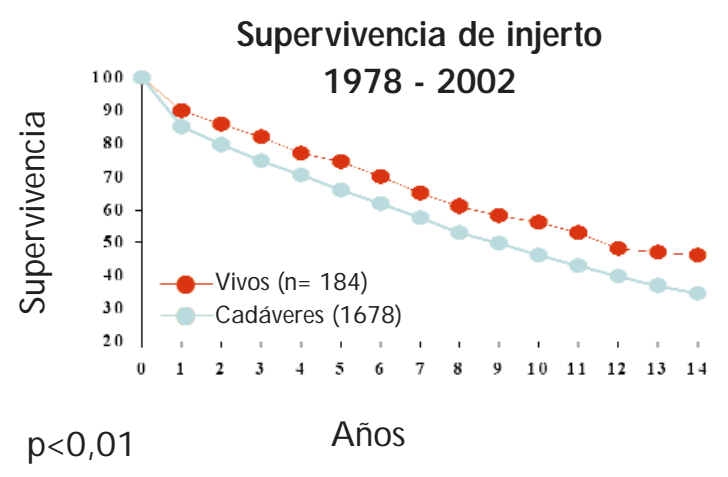

FIG URA 8.
FIG URA 7.

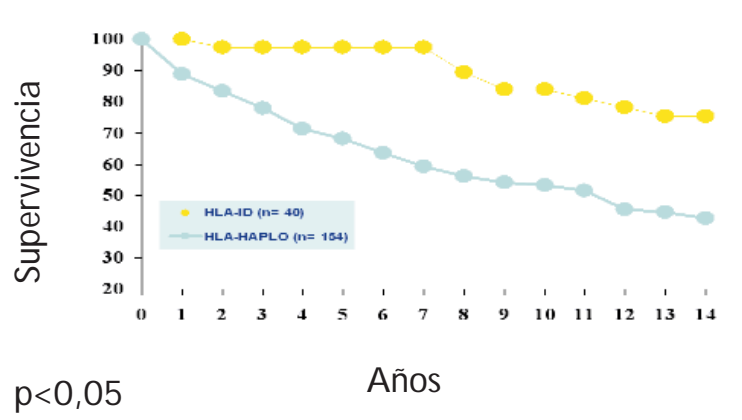

Trasplante renal de donante vivo Supervivencia de injerto

$1978-2002$ 


\section{Mejoría en la supervivencia del injerto}

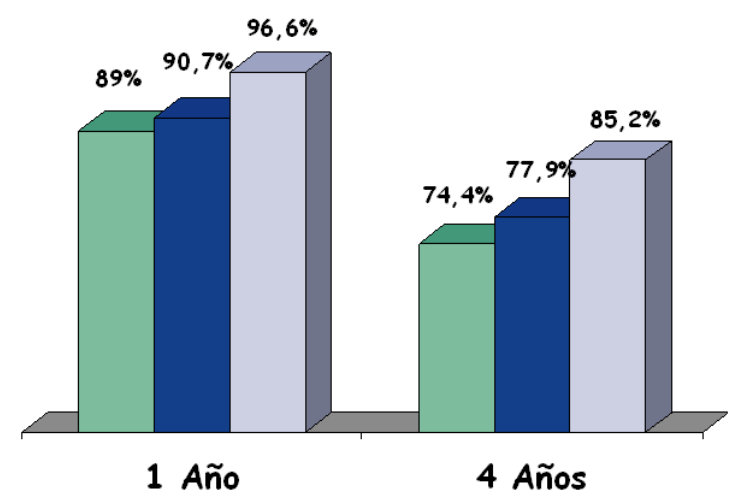

FIG URA 9.
Reducción en la incidencia de rechazo agudo

Pacientes libres de rechazo agudo

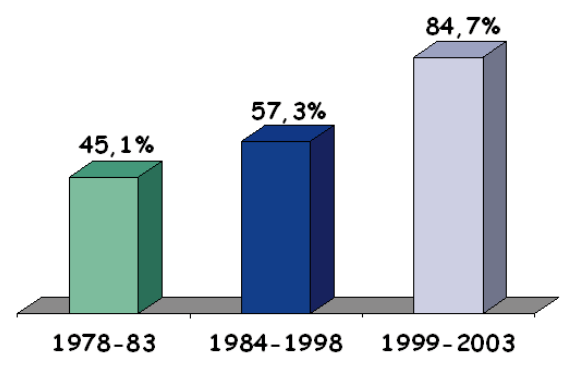

FIG URA 10.

\section{Evolución del paciente e injerto}

Basándonos en los datos analizados en la Unidad de Trasplante Renal de nuestro hospital, analizando la supervivencia del injerto, durante el periodo de 1999 a 2004, observamos una supervivencia del 97.55 al año, y una supervivencia del $86 \%$ a los 4 años. La supervivencia del paciente para el mismo periodo de tiempo es del $100 \%$ al año del trasplante y del $96.3 \%$ a los 4 años (un paciente fallecido por causa neoplásica, con injerto funcionante).

A continuación podemos observar las gráficas de supervivencia del injerto del periodo comprendido entre 1978 y 2004. La supervivencia del injerto de donante vivo es significativamente mejor que la de injerto de cadáver (Fig. 8), y si analizamos la supervivencia del injerto en cuanto al grado de compatibilidad HLA, observamos la favorable supervivencia del grupo HLA idéntico con una supervivencia del $67.2 \%$ a los 15 años, frente al grupo de HLA semiidéntico con una supervivencia para el mismo periodo del $38.4 \%$. (Figura 7).

También podemos ver en los gráficos, la mejoría en la supervivencia del injerto al año y a los 4 años, analizando los datos por etapas correspondientes a la el uso de diferentes inmunosupresores, etapa preciclosporina, ciclosporina y época actual con el uso de diferentes combinaciones nuevos fármacos. (Figuras 9 y 10 ).

\section{BIBUOGRAFIA y LECTURAS RECOMENDADAS (*lectura de interés y **lectura fundamental)}

1. BURGOS, F.J.; ALCARAZ, A.; CASTILlÓN, I. y cols.: "Present and future of kidney transplantation". Actas Urol. Esp., 26: 731,2002.

2. CASTILLÓN VELA, I.T.; MENDEZ, R.; MENDEZ, R.G. y cols.: "Kidney trasplantation from living donor: a review from experience". Actas urol. Esp., 25: 150, 2001.

3. CLAYMAN, R.V.; KAVOUSSI, L.R.; SOPER, N.J. y cols.: "Laparoscopy nephrectomy". N. Engl. J. Med., 324: 1370, 1991.

*4. GILL, I.S.; CARBONE, J.M.; CLAYMAN, R.V. y cols.: "Laparoscopic live-donor nephrectomy". J. Endo. Urol., 8: 13, 1994.

**5. FELIPE, C.; OPPENHEIMER, F.; PLAZA, J.J.: "Trasplante renal de vivo: una opción terapéutica real". Nefrología, 20: 8, 2000.

6. MERRILL, J.P.; MURRAY, J.E.; HARRIS, J.H. y cols.: "Succesful homotrasplantation of the human kidney between identical tweens". JAMA,160: 277,1956.

**7. PLAZA, J.J: "Trasplante renal de donante vivo." Nefrología, 21: 97, 2001.

8. RATNER, R.E.; CISECK, L.J.; MOORE, R.G. y cols.: "Laparoscopic live donor nephrectomy". Trasplantation, 60: 107, 1995.

*9. RATNER, L.E.; MONTGOMERY, R.A.; KAVOUSSY, L.R.: "Laparocpic live donor nephrectomy. A rewiew of the first 5 years". Urol. Clin. North Am., 28: 709, 2001.

10. VELA, E.; CLERIES, M.: "Renal transplantation in Catalonia, 1984-1997. Catalan Comité of the Registry of Renal Patients". Trasplant Proc., 3: 235, 1999.

11. MEMORIA DE ACTIVIDADES ONT. 2002. 